\title{
Article
}

\section{Correlation between MCAT Biology Content Specifications and Topic Scope and Sequence of General Education College Biology Textbooks}

\author{
Steven W. Rissing \\ Department of Evolution, Ecology, and Organismal Biology, Ohio State University, Columbus, OH 43210
}

Submitted February 2, 2013; Revised May 12, 2013; Accepted June 5, 2013

Monitoring Editor: Diane Ebert-May

\begin{abstract}
Most American colleges and universities offer gateway biology courses to meet the needs of three undergraduate audiences: biology and related science majors, many of whom will become biomedical researchers; premedical students meeting medical school requirements and preparing for the Medical College Admissions Test (MCAT); and students completing general education (GE) graduation requirements. Biology textbooks for these three audiences present a topic scope and sequence that correlates with the topic scope and importance ratings of the biology content specifications for the MCAT regardless of the intended audience. Texts for "nonmajors," GE courses appear derived directly from their publisher's majors text. Topic scope and sequence of GE texts reflect those of "their" majors text and, indirectly, the MCAT. MCAT term density of GE texts equals or exceeds that of their corresponding majors text. Most American universities require a GE curriculum to promote a core level of academic understanding among their graduates. This includes civic scientific literacy, recognized as an essential competence for the development of public policies in an increasingly scientific and technological world. Deriving GE biology and related science texts from majors texts designed to meet very different learning objectives may defeat the scientific literacy goals of most schools' GE curricula.
\end{abstract}

\section{INTRODUCTION}

Effective science education requires an instructor to balance explanations of scientific processes with presentations of factual content (Alberts, 2009). The balance and extent of these learning goals in any course should reflect the educational needs of the student audience targeted. College biology courses, especially gateway ones, target three rather distinct audiences: students preparing for the Medical College Admission Test (MCAT) and applying to medical schools; students starting undergraduate degree programs in biology and related science, technology, engineering, and mathemat-

DOI: $10.1187 /$ cbe.13-02-0017

Address correspondence to: Steven W. Rissing (rissing.2@osu.edu).

(C) 2013 S. W. Rissing. CBE-Life Sciences Education (C) 2013 The American Society for Cell Biology. This article is distributed by The American Society for Cell Biology under license from the author(s). It is available to the public under an AttributionNoncommercial-Share Alike 3.0 Unported Creative Commons License (http:/ / creativecommons.org/licenses/by-nc-sa/3.0).

"ASCB ${ }^{\circledR}$ " and "The American Society for Cell Biology ${ }^{\circledR}$ " are registered trademarks of The American Society for Cell Biology. ics (STEM) fields; and students fulfilling their institution's general education (GE) graduation requirements. Tension can exist among the above learning goals and the extent to which gateway courses balance them for these different audiences (Alberts, 2009). For example, the National Research Council's (NRC, 2003, p. 112) report, BIO2010, voices concern about the unintended impact of meeting the perceived needs of premedical students on the preparation of future biomedical researchers enrolled in courses taken by both. While scientists and science educators have justifiably focused on the needs and curricula of these two student audiences (NRC, 2003; American Association of Medical Colleges and Howard Hughes Medical Institute [AAMC-HHMI], 2009), they have less direct control over and have focused less attention on the needs of the much larger, third student audience of "nonmajor" students as they meet their GE graduation requirements.

In 2009, students receiving bachelor's degrees from American colleges and universities numbered 1,601,368 (National Center for Education Statistics, 2009). We can estimate the portion of that cohort that formed the GE science student audience by first recognizing that in that same year, AAMC medical schools received first-time applications from 31,063 students (AAMC, 2011a), approximately half of whom 
subsequently matriculated at those schools (AAMC, 2009a). Estimate that most of these applicants and matriculants took the MCAT the year before they applied (as recommended by the AAMC, 2009b) and assume that the number of students delaying medical school applications equals those applying who delayed applying previously. In 2008, the AAMC administered 75,809 MCATs (AAMC, 2008) to 65,954 individuals, given a retake rate of 13\% (AAMC, 2009b). Even allowing for a high level of attrition of students intending to apply to medical school between when they began college and decided not to take the MCAT, the vast majority of U.S. college students likely take GE courses in biology or related natural sciences as opposed to introductory majors courses taken by biology and other STEM majors and premedical students. The type and extent of factual content, the insights into the strengths and weaknesses of processes of scientific inquiry, and the balance of these learning goals should differ for this GE audience compared with the STEM major and premedical audiences.

Post-Sputnik initiatives to educate more STEM professionals (Gallagher, 2000) led eventually to the recognition that sound public policy in a modern democracy also requires "civic scientific literacy" (CSL), that is, the ability of citizens "to understand important policy disputes involving science or technology ... to discharge their (civic) responsibility in the context of an increasingly scientific society" (Miller, 2007, p. 2; see also Snow, 1959; American Association for the Advancement of Science [AAAS], 1990; Miller, 1998). For this same reason, the National Science Foundation (1996, p. ii) has stated, "America's undergraduates-all of them-must attain a higher level of competence in (STEM)" (emphasis in original) and recently reiterated this position (AAAS, 2009). The undergraduate advising Web pages of the 10 largest public universities in the United States list GE graduation requirements that include one or more courses in biology or other natural sciences and justify this requirement on the basis of promoting CSL. Although these institutions comprise only $1.5 \%$ of all public, bachelor's degree-granting institutions, they awarded $8.4 \%$ of the bachelor's degrees granted by public institutions in the United States in 2009 (institutional data from http://nces.ed.gov/ipeds/datacenter). The GE curriculum, unique to American higher education (Miller, 2010), likely explains higher CSL scores among Americans compared with Europeans (28\% and 14\%, respectively; Miller, 2007).

If the perceived needs of premedical students impact courses for STEM majors, as argued by the NRC (2003), then the perceived needs of both of those audiences may also impact biology and similar natural science courses for students in the much larger GE audience. To examine these sorts of impacts on different student audiences taking gateway biology courses, I have compared the MCAT biology content specifications with the scope and sequence of topics in biology textbooks intended by their publishers for introductory majors or GE courses.

I focus on introductory-level courses, because most AAMC medical schools only require applicants to complete $1 \mathrm{yr}$ of college biology, almost always as a 1-yr, majors sequence (AAMC, 2011b). Further, only 51.2\% of medical school applicants and matriculants received bachelor's degrees in biology (AAMC, 2009c), confirming NRC's (2003, p. 5) observation that "departments of physics, chemistry, and mathematics, as well as departments of biology, feel pressure to cover the material tested on the MCAT in their introductory courses (for biology and other STEM majors) to the exclusion of other potential topics." I use textbooks as a convenient assay of the curricula for which they are developed and marketed, because groups of gateway course instructors and other stakeholders tend to make textbook adoption decisions together with other decisions regarding learning objectives of the course(s), curricula, and syllabi. Individual instructors, especially in large, GE biology courses taught increasingly by affiliated faculty, often play no role in developing curricula, establishing learning objectives, or deciding on a syllabus, much less the choice of a textbook to support a consensus course syllabus.

The AAMC surveys medical school faculty and students extensively to determine relative importance ratings of MCAT biology and other science content specifications; it then surveys instructors of introductory majors biology courses, those required by AAMC medical schools, to establish the extent to which those instructors include candidate MCAT topics in their majors introductory biology courses. The resulting, final MCAT importance ratings (MIR) fortuitously facilitate an analysis of MCAT impact on scope (number or percent of MCAT topics included in a text) and sequence (regression of a topic's MIR with standardized starting page in a text) of introductory majors and GE biology curricula as revealed in textbooks for these courses.

\section{METHODS}

\section{Scope and Sequence of MCAT Biology Content Specifications}

As described in research reports posted on its website, the AAMC determines MCAT biology and other content specifications and the relative importance of specific topics through the following process: 1) The AAMC staff develops "lists of science topics and sub-topics, compiled from a review of the top-selling undergraduate introductory biology [and other science] ... text books" (AAMC, 2001, p. 1). 2) They survey a stratified sample of medical school faculty members and students to rank those candidate topics by importance for entering medical students on a Likert scale (where $5=$ most important, $1=$ least important). The mean of these responses for each topic constitutes its MIR (AAMC, 2001). 3) They establish a tentative cutoff MIR $\geq 2.25$ for inclusion in MCAT content specifications (represented by a scissors icon in Figures 1 and 2 below). 4) They then survey "faculty teaching introductory science courses at a sample of undergraduate schools [to determine whether each topic is] ... covered sufficiently in undergraduate introductory science courses" (AAMC, 2002, p. 1) by asking a sample of those faculty members to rank topics on a Likert scale $(4=$ covered in greater depth, $1=$ not covered at all), with a cutoff at which "at least $70 \%$ of the institutions indicated coverage at a minimum or higher level" required for inclusion in the MCAT content specifications (AAMC, 2002, p. 2). 5) They base final MCAT content specifications on these responses, such that included topics exceed both cutoffs. 6) They post the final biology and other content specifications for the MCAT on the AAMC website (for current MCAT version, see AAMC, 2002, pp. 9-10; for the 2014 MCAT, see AAMC, 2010). The AAMC (2009b) also 
Table 1. Texts surveyed for biology/STEM majors and GE courses from two publishers ${ }^{\mathrm{a}}$

\begin{tabular}{|c|c|c|c|c|c|c|c|c|}
\hline Publisher & Author(s) & (C) Year & Edition & Title & ISBN & Text pages ${ }^{b}$ & Text words ${ }^{c}$ & Audience $^{\mathrm{d}}$ \\
\hline Benjamin Cummings & N. A. Campbell et al. & $2008 \mathrm{~b}$ & 8 th $^{\mathrm{e}}$ & Biology & 9780321543257 & 1393 & 486,107 & Majors \\
\hline Benjamin Cummings & $\begin{array}{l}\text { N. A. Campbell, J. B. } \\
\text { Reece, M. R. Taylor, } \\
\text { E. J. Simon, and J. L. } \\
\text { Dickey }\end{array}$ & 2009 & 6th & $\begin{array}{l}\text { Biology Concepts E } \\
\text { Connections }\end{array}$ & 9780321489845 & 781 & 324,433 & GE-Lg \\
\hline Benjamin Cummings & $\begin{array}{l}\text { N. A. Campbell, J. B. } \\
\text { Reece, and E. J. Simon }\end{array}$ & 2007 & 3 rd & Essential Biology ${ }^{\mathrm{f}}$ & 0805368426 & 462 & 142,957 & GE-Sml \\
\hline Benjamin Cummings & S. Freeman & 2008 & $3 \mathrm{rd}$ & Biological Science & 9780132249850 & 1262 & $\mathrm{~N} / \mathrm{A}$ & Majors \\
\hline McGraw-Hill & $\begin{array}{l}\text { R. J. Brooker, E. P } \\
\text { Widmaier, L. E. } \\
\text { Graham, and P. D. } \\
\text { Stiling }\end{array}$ & 2008 & 1 st & Biology & 9780072956207 & 1300 & $\mathrm{~N} / \mathrm{A}$ & Majors \\
\hline McGraw-Hill & $\begin{array}{l}\text { J. B. Losos, K. A. Mason, } \\
\text { S. R. Singer, P. H. } \\
\text { Raven, and G. B. } \\
\text { Johnson }\end{array}$ & 2008 & 8th & Biology & 9780072965810 & 1260 & $\mathrm{~N} / \mathrm{A}$ & Majors \\
\hline McGraw-Hill & S. S. Mader & $2010 a$ & 10th & Biology & 9780073525433 & 907 & 282,450 & $\begin{array}{l}\text { "Majors" by } \\
\text { publisher }\end{array}$ \\
\hline McGraw-Hill & S. S. Mader & 2009 & $1 \mathrm{st}$ & Concepts of Biology & 9780073403458 & 795 & 277,969 & GE-Lg \\
\hline McGraw-Hill & S. S. Mader & $2010 b$ & 2nd & Essentials of Biology & 9780073403427 & 602 & 171,838 & GE-Sml \\
\hline
\end{tabular}

${ }^{\mathrm{a}} \mathrm{GE}$ texts from both publishers exist in GE-Lg and GE-Sml versions.

${ }^{b}$ Does not include appendices, answers to questions, table of contents.

${ }^{\mathrm{c} B a s e d}$ on word processor counts of digitized scans of text pages, exclusive of non-core text material embedded in each chapter, such as end-of-chapter questions, further reading lists, text boxes, and so on.

dBased on publisher's description.

eThis edition acknowledges 772 faculty reviewers.

${ }^{\mathrm{f}}$ Text excludes human physiology.

publishes the MCAT content specifications (without MIR values) in its Official Guide to the MCAT Exam.

The AAMC groups its biology content specifications for the current (2003) and future (2014) MCAT version into four major divisions, each containing primary and nested secondary, tertiary, and a few fourth-order subtopics (due to their small number, I grouped fourth-order subtopics into their parent tertiary subtopics). For example, the biology content specifications include the following nested topics: "II. CELLULAR BIOLOGY [division] ..., L. EUKARYOTIC CELL: MITOSIS [primary topic] ..., 1. Mitotic structures (secondary subtopic) ..., b. chromatids, centromeres, kinetochores [tertiary subtopic]" (AAMC, 2002, 2009b). In the 2003 surveys, this primary topic (mitosis) and its nested subtopics (chromatids, centromeres, etc.) appeared on the final, posted MCAT content specifications. The AAMC determines MIRs only for primary MCAT topics.

Generally, I could map the presence or absence of an MCAT primary topic directly to one section of the biology textbooks I analyzed; a few topics, however, required special attention in my analysis of texts or in comparing the 2003 and 2014 MCAT biology content specifications. The 2003 and 2014 surveys included the primary topic of "Genetics-analytical methods" with a MIR of 2.08. This topic contained secondary topics of "Hardy-Weinberg principle" and "Test cross: back cross; concepts of parental, F1, and F2 generations." Because most textbooks treated these as separate topics, I treated these both as separate primary topics, each with an MIR of 2.08. The AAMC added the 2003 primary topic "Excretory system" to the list of secondary topics under primary topic of "Digestive system" in the 2014 MCAT content survey and specifications.
The 2003 and 2014 AAMC surveys included a primary topic of "Cell theory," which appeared in several surveyed texts but only in introductory material and then in a cursory manner; I did not include this topic in my comparisons. The primary topics, "Individual vertebrate behavior" (MIR = 2.17 in 2003) and "Behavioral relationships" (MIR $=1.96$ in 2003) proved indistinguishable in most texts; therefore, I included only the former topic in my comparisons. The 2014 survey included a new division of "Integrative and Systems Biology" with two new primary topics that are not included here due to the small number of primary topics and relatively low MIR values.

\section{Scope and Sequence of Introductory and GE Biology Textbooks}

I determined the scope and sequence for all primary topics, that is, those with calculated MIRs reported by AAMC and those included in final MCAT biology content specifications, in five introductory majors biology textbooks. I determined intended audience of all texts examined (Table 1) by consulting publishers' descriptions of their texts on their websites and/or from materials accompanying examination copies of the texts. The publisher of one text described its text as appropriate for "mixed" audiences, that is, majors and nonmajors. For this analysis, I considered this text (Mader, 2010a) as an introductory majors text, given its length relative to all other texts. College text publishers do not disseminate information regarding the adoption rates or adopting courses of their texts; therefore, I chose to examine all current texts sent by publishers for possible course adoption to the Center for Life 
Sciences Education, which teaches freshman-level, gateway biology courses to more than 9000 students per year at Ohio State University.

For each text intended for adoption in an introductory majors biology course, I recorded each MCAT primary and nested topic it presented and the starting page of that presentation. If a text presented a primary MCAT topic in multiple places, I selected the section with the largest number of subtopics included and recorded the first page of that section as the topic's starting page in that text. For example, "mitosis" usually appears at several places in texts, but the major discussion in each text could be determined on the basis of the number of subtopic terms (inevitably in association with richly labeled illustrations of the sequence). To permit comparisons among texts of the presentation sequence of MCAT topics, I transformed the above starting-page numbers for MCAT topics by dividing each starting-page number by the total number of text pages (excluding appendices, glossaries, photo credits, study questions and answers, index, etc.), which resulted in a standardized percentile start page for each topic included in each text. I could then regress the percentile start pages of primary MCAT topics in a text against the MIRs for those topics and among texts. Transformation of percentile starting-page values to achieve a normal distribution of observations did not alter statistical interpretation of any results and is therefore not included here.

The publishers of two of the above introductory majors texts also produce two separate GE biology textbooks each. The two GE texts of both publishers vary in length; where necessary, I differentiate between each of these publisher's GE-large (GE-Lg) and GE-small (GE-Sml) texts. I expanded the analysis of the sequence of primary MCAT topics to these GE texts by recording the pages on which all primary MCAT topics occurred in them and calculating the percentile start page for that topic as described for majors texts above. The two sets of introductory majors, GE-Lg, and GE-Sml texts had identical (Mader, 2009, 2010b) or overlapping (Campbell et al., 2007, 2009) authors and shared production teams within their publishers. Data on the texts sampled appear in Table 1. One GE-Sml text (Campbell et al., 2007) explicitly excluded all human physiology topics, for which I corrected in calculating scope and MCAT term density.

For the two sets of introductory majors, GE-Lg, and GESml texts I determined scope of inclusion of MCAT topics in each text by noting whether each of them discussed every primary MCAT topic and its nested, subtopics. When an MCAT subtopic included multiple terms (see example above), I scored that topic only once if the text discussed any of those multiple terms. To compare MCAT term density between and among these two sets of texts, which varied in page dimensions and non-text materials, I calculated primarytertiary MCAT term density per standard number of text words in each text. I divided the number of first-order-thirdorder MCAT terms determined above by the total number of text terms of each text. To determine the number of words in each text, I first optically scanned each (despined) text, using the scan and double-sided original settings of an office photocopy machine to produce a PDF file for each chapter. I then used the standard optical character recognition (OCR) function of Adobe Acrobat Pro 9 to render the PDF files readable, and copied and pasted each chapter file into a Microsoft Word file, in which I used the spell-check function to detect and correct OCR errors and to exclude non-core text material embedded in each chapter, such as end-of-chapter questions, further reading lists, text boxes, and so on. I then used the word count utility of the Microsoft Word spell-checker to determine the number of words in each chapter of each text. I summed the word count for each chapter in each text and divided the number of MCAT terms in each text (determined above) by this word total to arrive at the MCAT term density per 10,000 text words for each text. Because MCAT and total text term number values are exact counts and not estimates, I cannot report means and SDs.

\section{RESULTS}

\section{Scope and Relative Importance Ratings of MCAT Biology Content Specifications}

Respondents to AAMC's surveys ranked topics in the Molecular biology and genetics and Cellular biology divisions as most and equally important for entering medical students to know for the 2003 (current) MCAT version (Figure 1). The mean MIR calculated by AAMC for molecular biology and genetics exceeds the other three divisions for the 2014 (planned) MCAT. Respondents for the current MCAT include more topics in biology of body systems division than the other three. They rank topics in the Developmental, organismal, and population biology division, which includes the primary topic "Evolution," as the least important and least numerous for the current and planned MCAT. The mean MIR of all four biology divisions increases between 2003 and 2014, as does number of topics and subtopics, especially in the molecular/cellular divisions (Figure 1).

\section{Sequence of MCAT Content Terms in Introductory Majors and GE Biology Textbooks}

The presentation sequence of topics in all introductory majors and GE texts examined correlates significantly with the AAMC-determined MIR of those primary topics (Figure 2), even after Bonferroni correction of the significance levels, given the multiple comparisons made. Molecular and cellular topics with higher MIRs appear earlier in biology texts than population, community, and evolution topics with lower MIRs, such that all texts, no matter the intended audience, employ a small-to-large order of topic presentation. All texts sampled include their main discussion of at least $50 \%$ of the primary MCAT biology content specifications within the first $30 \%$ of the text. The small number of MCAT terms between the 50th and 70th percentile pages of all texts (Figure 2) coincides with the plant biology and organismal diversity parts of those texts, topics not included in the MCAT biology content specifications.

\section{Scope of MCAT Content Terms in Introductory Majors and GE Biology Textbooks}

All five introductory majors texts sampled included all $(n=$ 51) or all but one of the primary MCAT content specifications, that is, those with MIRs determined through AAMC's surveys of MCAT stakeholders. Within the two sets of majors, GE-Lg, and GE-Sml biology texts, standardized density of all MCAT terms (primary through tertiary) in the GE texts either 


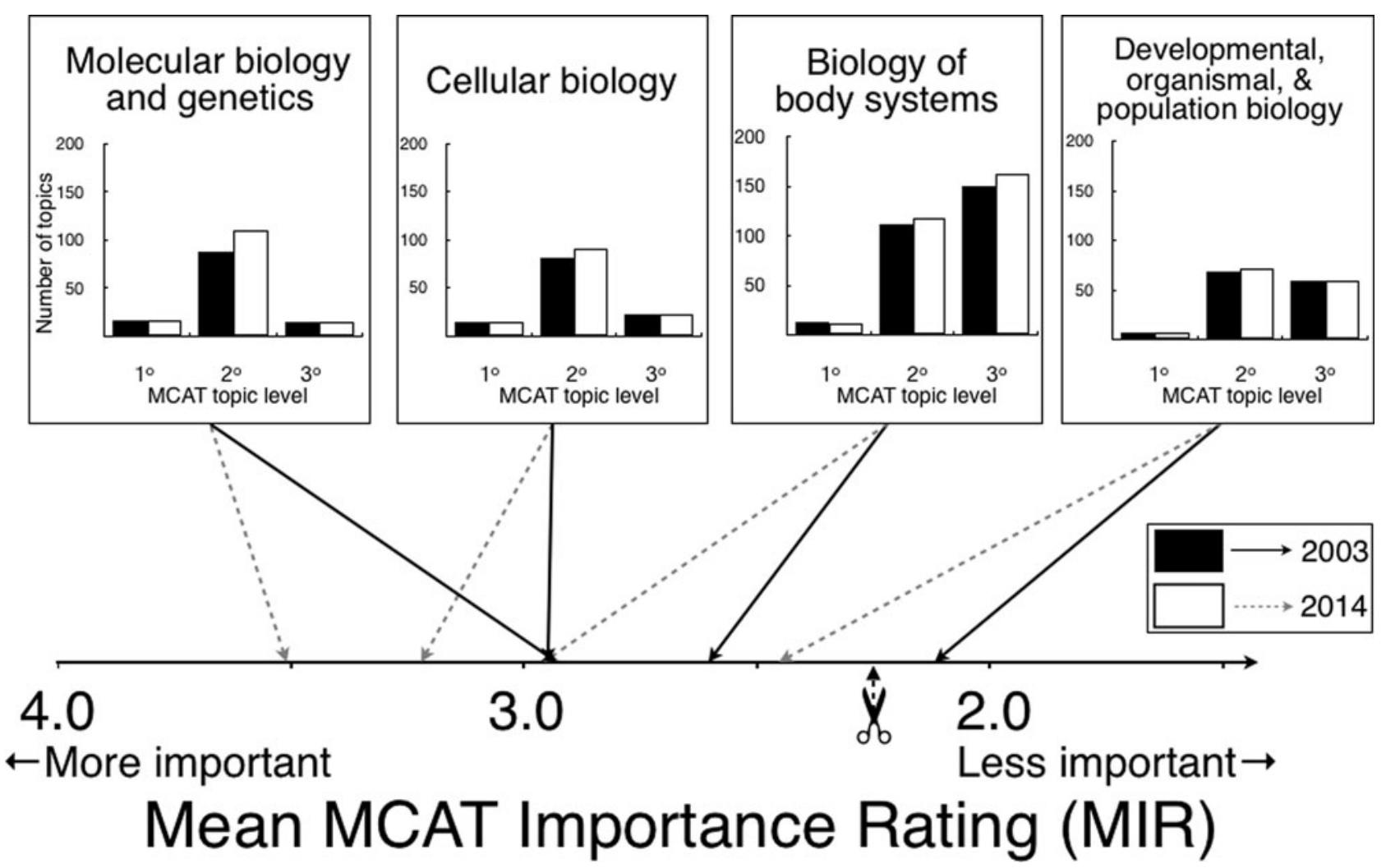

Figure 1. The scope of coverage and relative importance rating of biological topics/subtopics as determined by the AAMC for the 2003 and 2014 MCAT. Nested topics $\left(1^{\circ}, 2^{\circ}\right.$, and $3^{\circ}$ ) are arranged along an axis according to MIR of all primary topics within each of AAMC's four divisions of biology from "most important" $(=5.0)$ to "least important" $(=1.0)$. The scissors icon at MIR = 2.25 indicates the cutoff for inclusion in the MCAT content specifications for each individual primary topic. Histograms show frequency distribution of nested topics within each division.

equals or more often exceeds that of the corresponding majors text by the same author(s) and publisher (Figure 3). Texts for GE biology courses are more MCAT-term dense than are texts for introductory biology majors courses, the only biology courses required by the AAMC for students applying to its medical schools.

I determined the correlation between AAMC's MIR and the percentile starting page of each primary MCAT topic in each of the nine texts sampled (Table 1), which independently resulted in regression lines for all texts with similar slopes and intercepts (values in Figure 2). The similarity in sequence of topic presentation among texts regardless of intended student audience, majors versus GE, becomes apparent when comparing the topic sequence of texts for those different student audiences produced by the same author(s) and publisher. Using percentile starting page (defined above) for primary MCAT topics included in each text to permit comparisons among texts, the order of topic presentation in both GE texts of both publishers correlates strongly with the topic presentation of the majors text of that same publisher (and the other publisher as well).

Not only do the GE texts present topics in nearly identical sequence to their corresponding majors text (Figure 4), but they employ similar, albeit abridged, wording (Table 2). The abridging process seems to start with the majors text with biological content and text terms deleted some to result in the larger GE and deleted more to result in the smaller GE text. I provide one example of this process and its result on GE texts in the discussion of differences in cytokinesis in plants and animals in three texts by Campbell and various other authors (Table 2). While some concepts and terms appear in the majors text and the two GE texts (e.g., cytokinesis, cleavage, cleavage furrow, and cell plate), others do not (the majors and GE-Lg texts note that contracting microfilaments in cell division are made of actin and associated with myosin, but the GE-Sml text discusses the microfilaments without mentioning actin and myosin).

This tendency to abridge text from either publisher's majors text to derive the GE text extends to majors text figures that appear in simplified format in derived GE texts by the same author(s) and publisher (Table 3). This occurs even though the derived GE figures are usually the same size as the original majors figure; that is, the reduced size of figures in GE texts did not force reduction in terminology or explanation. These reductions in information content of majors textbooks to derive GE textbooks often seem arbitrary and counterproductive to the learning objectives of many GE biology courses. For example, the illustrated time line accompanying the discussion of the evolution of humans in Campbell et al.'s (2008b) majors text has a sample size of 16 "selected hominid species" (Figure 5) while the "time line of human evolution" accompanying the same text discussion in Campbell et al.'s 


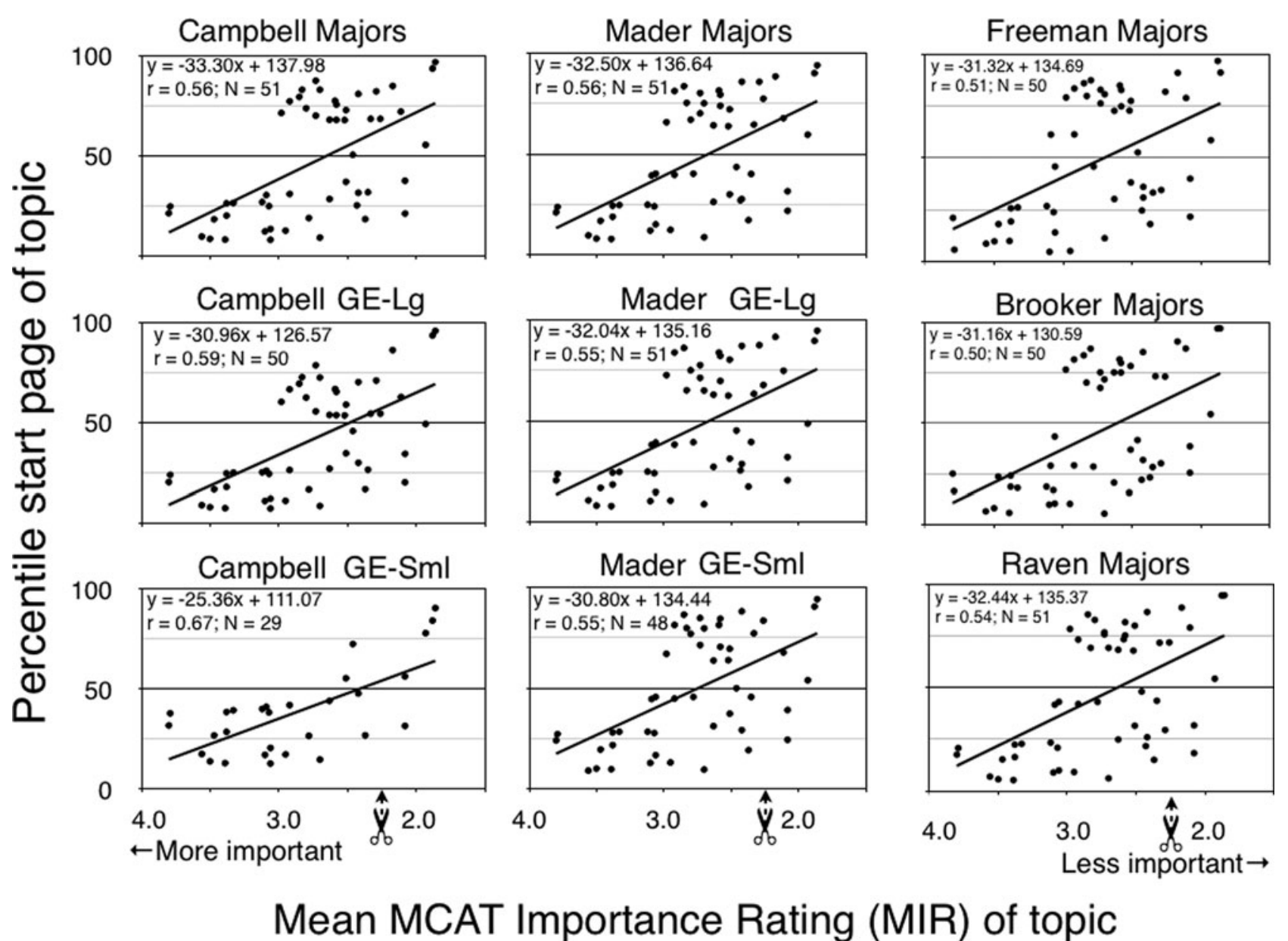

Figure 2. Standardized textbook page of appearance of MCAT primary topics against plotted MIR for a sample of college biology texts. Scissors icon at MIR $=2.25$ indicates cutoff for inclusion in MCAT content specifications for primary topics. Left column, majors text (top) and two GE texts (large in middle row, small in bottom row) by Pearson Education. Middle column, same for texts from McGraw-Hill Education. Right column, same for three additional majors texts. Texts as in Table 1.

(2007) GE-Sml text only has a sample size of nine species (an additional species is lost due to a one-million-year reduction in the time span of the latter figure.) The corresponding figure for Campbell et al.'s (2009) GE-Lg text has a sample size of 14 species (Figure 5).

\section{DISCUSSION}

Textbooks for GE biology courses are derived from texts for introductory majors biology courses and their premedical and STEM audiences. These majors texts align with the scope and sequence (MIRs) of AAMC's MCAT biology content specifications, consistent with NRC's concerns about the negative impact of MCAT preparation on majors curricula and interest in efforts to improve/reform the MCAT (NRC, 2003; AAMCHHMI, 2009). When the NRC (2003, p. 112) concluded that "a change in the MCAT itself, or in the way it is used for medical school admissions, would allow the biology curriculum to develop in a way that is beneficial to all students instead of allowing the content of the MCAT to dictate what students are taught," "all students" referred to the preparation of future biomedical researchers. Their recommendation ex- tends, however, to the preparation of all college graduates who will shape STEM public policy. AAMC has responded to such concerns about the impact of MCAT preparation on STEM majors and premedical audiences with an extensive review and reform of the exam (AAMC-HHMI, 2009) intended

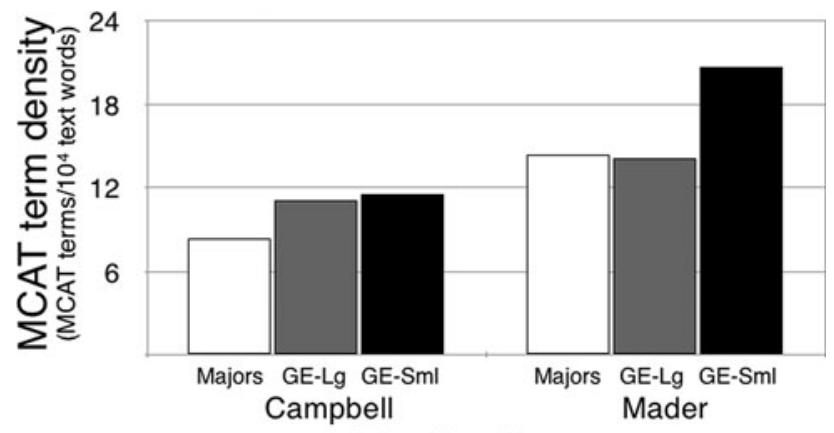

Text/audience

Figure 3. Density of terms included in MCAT biology content specifications found in introductory majors and two GE texts from two publishers (see Table 1). 


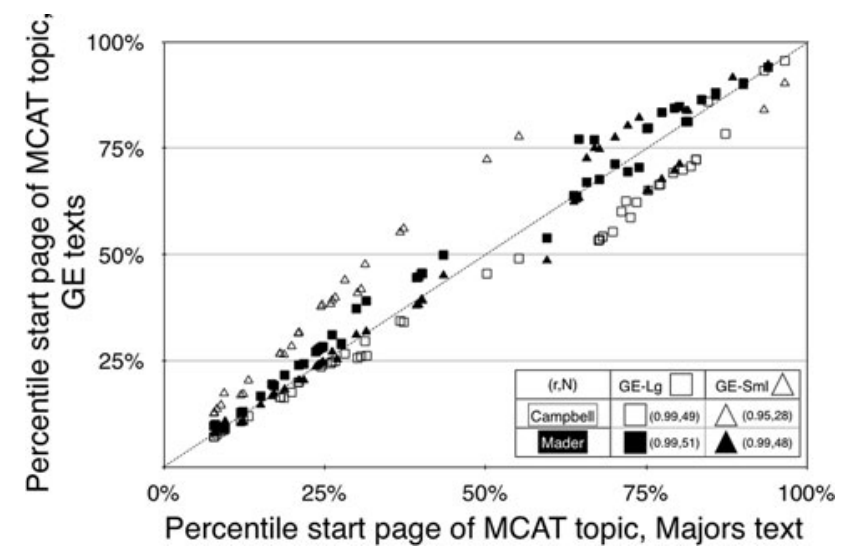

Figure 4. Correlations between topic sequences in GE texts and introductory majors text of the same publisher for two sets of GE texts from two publishers (see Table 1). Percentile start page indicates the percentile point in a text (observed page divided by total number of text pages) in which the main discussion of a primary topic in the MCAT biology content specifications appears.

to place greater emphasis on critical analysis and reasoning skills.

Most American colleges and universities require students to complete GE science courses, including and especially biology, to promote CSL. Textbooks for this GE audience, however, do not appear designed for it. Deriving GE biology textbooks from larger, majors books, as appears the case in the two sets of majors and GE texts examined here, assumes that those majors texts contain all content and employ appropriate pedagogy to accomplish the CSL goals of the GE curriculum and meet the science learning needs of GE students. Even if the concordance between scope and sequence of majors and GE texts and MCAT MIRs is only correlational, the reductionist approach to learning used in many STEM majors courses may not suite the learning styles or CSL educational needs of GE students. Publishers often soften this reductionist approach by adding several human-interest essays in their GE texts. The resulting GE texts nonetheless reveal the content constraints of their majors source texts.

Abridging a majors text while generating GE texts (Table 2) may unintentionally support common biological misconceptions among GE students. For example, presenting GE audiences with fewer observations on which current hypotheses of hominid evolution are based (Figure 5) might facilitate widespread misconceptions about the observational support for evolution (Miller et al., 2006) among those students. These practices may also fail to meet the CSL learning needs of the GE audience or an institution's GE learning objectives. Current STEM policy issues confronting college graduates include natural and social responses to climate change, recognition of biodiversity loss, and application of new genomics technologies in healthcare and agriculture. These issues provide engaging, interdisciplinary cases for framing GE biology courses and promoting CSL. These "big picture" topics, however, receive MIR values below the cutoff for inclusion in the MCAT biology content specifications, or they are not even included in AAMC's surveys. As noted by Muller (1959), these topics appear at the back of majors texts-and their smaller GE versions-where instructors and students often never reach them. At the same time, texts designed for GE courses include technical content more relevant for students preparing for the MCAT and graduate careers in specialized fields. For example, the apparently arbitrary reduction of technical terms in the comparison of cytokinesis in plants and animals (Table 2, and see also Table 3) reveals not only the deletion of some terms but the retention of others that likely seem equally esoteric to a GE student concerned about climate change.

College GE biology texts also appear designed for a first course in science, reintroducing the scientific method, chemical structure of water, thermodynamics, and other basics. Within biology, such cursory coverage ignores recent K-12 curriculum reform through efforts such as the Next Generation Science Standards (NRC, 2012). The criticism of past K-12 STEM curricula as "a mile wide and an inch deep" (Schmidt et al., 2002) applies to current GE biology textbooks and many curricula in which they are used. Absent explicit linkage of K-12 and college GE STEM curricula, relevancy and effectiveness of both suffer. Providing GE students opportunities to review, update, and apply STEM concepts learned in K-12 years and to study with widely available digital resources designed for student-directed review and remediation of those concepts can meet a core learning goal that students "learn how to learn" inherent in most GE STEM curriculum justifications.

While the MCAT may not emphasize content knowledge (Zheng et al., 2008), the published MCAT biology content specifications and college biology texts for majors and GE courses do. The AAMC determined its MCAT biology content specifications through surveys of faculty and students of medical schools and biology "faculty [members] teaching introductory courses at [each] ... undergraduate school $[n=166] \ldots$ that had supplied at least ten [recent] MCAT examinees" (AAMC, 2002, p. 1). The AAMC staff compiles the topics for these surveys "from a review of the top-selling undergraduate [majors] biology... text books" (AAMC, 2001, p. 1). This process may limit statistical independence. Topic surveys that generate the MCAT content specifications are based on popular textbooks used in courses taken by students "who want to score well on (the MCAT)" (NRC, 2003, p. 112). Instructors of introductory majors biology courses that generate many MCAT examinees particpate in AAMC's undergraduate content survey, and they choose the majors textbook for their students, including many preparing for the MCAT. "Bundling" majors texts with cross-referenced, jointly authored MCAT preparation guides (e.g., Campbell et al., 2008a) may also limit statistical independence of this process. Providing honoraria to majors biology instructors, including some likely to participate in AAMC's surveys, to review majors texts that they may adopt for their courses and require their students to purchase may further limit the independence of AAMC's topic surveys. For example, one majors text acknowledges 772 faculty reviewers, increasing the probability that text reviewers will also complete AAMC content surveys. While the AAMC will introduce a competencybased MCAT in 2014 (AAMC-HHMI, 2009), the content specifications for that exam depended on the same survey process and the same topic list used to develop the current and past MCAT versions (AAMC, 2010). Indeed, the 2014 MCAT has an almost identical and slightly larger list of biology topics with higher mean biology MIRs than the current one (Figure 1). 
Table 2. Concordance among three biology texts describing the process of cytokinesis in a textbook for students majoring in biology and related STEM fields (left) and two textbooks for GE biology courses (GE-Lg in middle and GE-Sml at right) ${ }^{\mathrm{a}}$

Campbell et al., 2008b, Biology, 8th ed., pp. 234-236 Majors

$\longrightarrow$

Cytokinesis generally begins during anaphase or telophase, and the spindle eventually disassembles.

\section{Cytokinesis: A Closer Look}

In animal cells, cytokinesis occurs by a process known as cleavage.

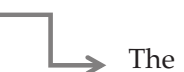

first sign of cleavage is the appearance of a cleavage furrow, a shallow groove in the cell surface near the old metaphase plate (Figure 12.9a). On the cytoplasmic side of the furrow is a contractile ring of actin microfilaments associated with molecules of the protein myosin. (Actin and myosin are also responsible for muscle contraction and many other kinds of cell movement.)

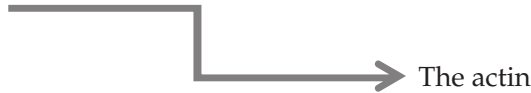

microfilaments interact with the myosin molecules, causing the ring contract. The contraction of the dividing cell's ring of microfilaments is like the pulling of drawstrings. The cleavage furrow deepens until the parent cell is pinched in two, producing two completely separated cells, each with its own nucleus and share of cytosol, organelles, and other subcellular structures.

Cytokinesis in plant cells, which have cell walls, is markedly different. There is no cleavage furrow. Instead, during telophase, vesicles derived from the Golgi apparatus move along microtubules to the middle of the cell, where they coalesce, producing a cell plate (Figure 12.9b). Cell wall materials carried in the vesicles collect in the cell plate as it grows. The cell plate enlarges until its surrounding membrane fuses with the plasma membrane along the perimeter of the cell.

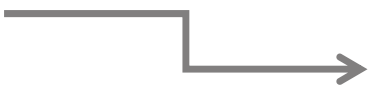

Two daughter cells result, each with its own plasma membrane. Meanwhile, a new cell wall arising from the contents of the cell plate has formed between the daughter cells.
Campbell et al., 2009, Biology Concepts E Connections, 6th ed., pp. 132 GE-Lg
Campbell et al., 2007, Essential Biology, 3rd ed., pp. 127-128 GE-Sml

\section{Cytokinesis differs for plant and} animal cells

Cytokinesis, or division of one cell into two, typically begins during telophase, although it may begin in late anaphase.

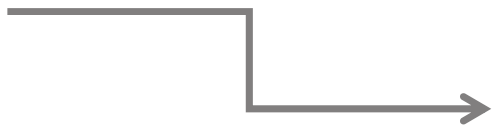

In animal cells, cytokinesis occurs by a process known as cleavage.

As shown in Figure 8.7 A, the first sign of cleavage is the appearance of a cleavage furrow, a shallow groove in the cell surface.

At the site of the furrow, the cytoplasm has a ring of microfilaments made of actin, associated with molecules of the protein myosin. (Actin and myosin are the same proteins responsible for muscle contraction-see

Module 30.8.) When the actin microfilaments interact with the myosin, the ring contracts,

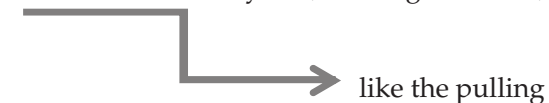

of drawstrings. The cleavage furrow deepens and eventually pinches the parent cell in two, producing two completely separate cells, each with its own nucleus and share of cytoplasm.

Cytokinesis is markedly different in plant cells, which possess cell walls.

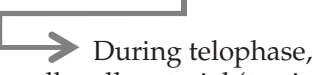

vesicles containing cell wall material (tan in figure) collect at the middle of the parent cell. The vesicles fuse, forming a membranous cell plate. The cell plate grows outward, accumulating more cell wall materials as more vesicles fuse with it. Eventually, the outer edges of the cell plate fuse with the plasma membrane, and the cell plate's contents join the parental cell wall.

The result is two daughter cells, each bounded by its own plasma membrane and cell wall.
Cytokinesis, the actual division of the cytoplasm into two cells, typically occurs during telophase.

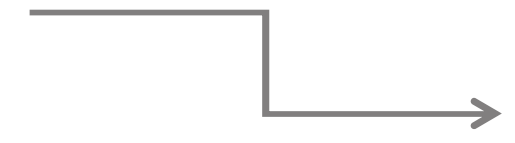

In animal cells, the cytokinesis process is known as cleavage.

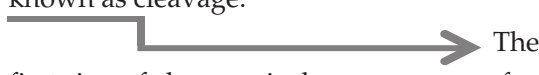

first sign of cleavage is the appearance of a cleavage furrow, an indentation at the equator of the cell.

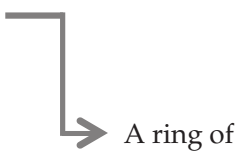

microfilaments in the cytoplasm just under the plasma membrane contracts,

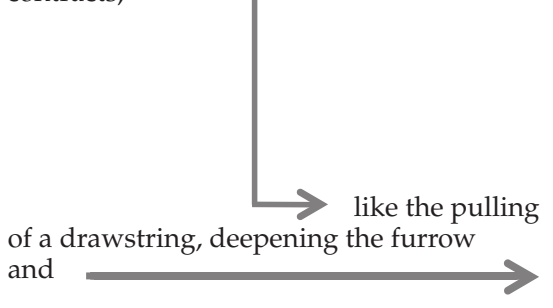

pinching the parent cell in two (Figure 8.9a, see page 128).

Cytokinesis in a plant cell occurs differently.

Membrane-enclosed vesicles containing cell wall material collect at the middle of the cell.

The vesicles gradually fuse, forming a membranous disk called the cell plate. The cell plate grows outward, accumulating more cell wall material as more vesicles join it.

Eventually, the membrane of the cell plate fuses with the plasma membrane, and the cell plate's contents join the parental cell wall, resulting in two daughter cells (Figure 8.9b).

${ }^{a}$ All three texts share some authors and are from the same publisher (Benjamin Cummings). Text is aligned vertically in columns to demonstrate content similarity reading from left to right across columns. Gray arrows indicate gaps relative to the other texts. Boldfaced type is retained from the original text. 
Table 3. Pedagogical impact of editing of figures in GE texts (GE-Lg or GE-Sml) derived from introductory majors biology texts by same author(s)

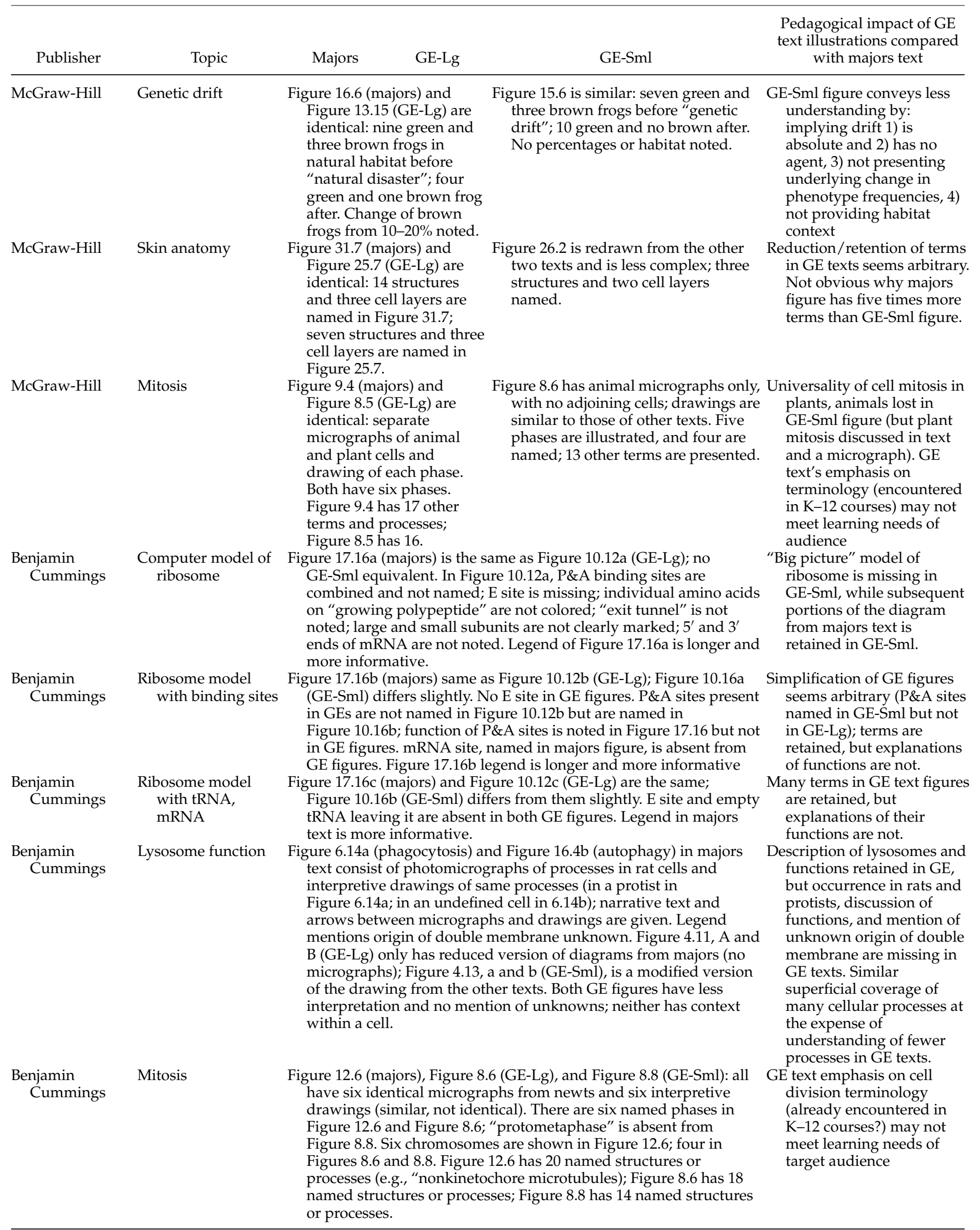



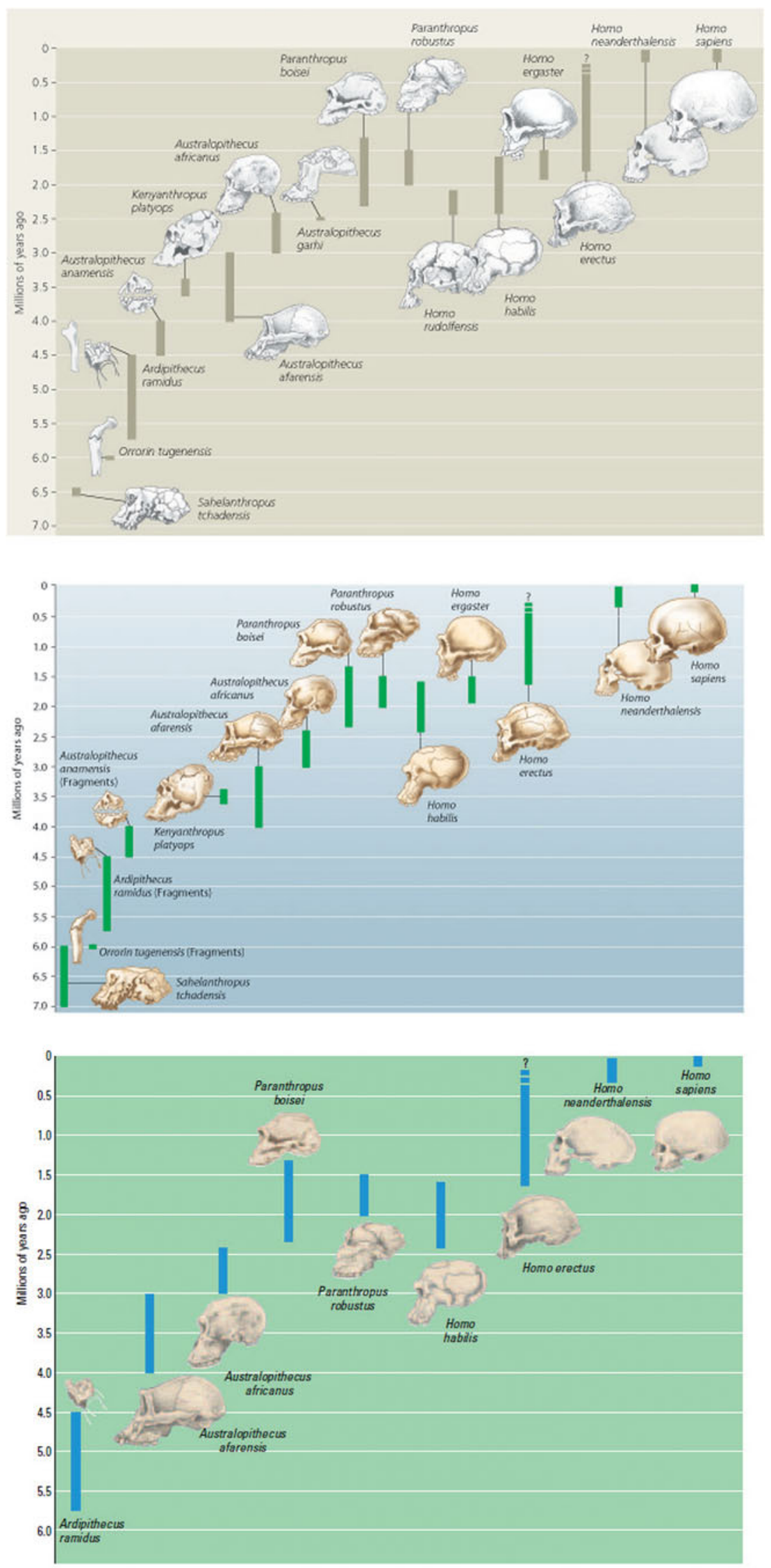

Figure 5. Figures displaying time line of recent hominid evolution from a text for students majoring in biology and related STEM areas (top, Campbell et al., 2008b, p. 729) and two texts for GE biology courses (middle, GE-Lg, Campbell et al. 2009, p. 403; bottom, GE-Sml, Campbell et al., 2007, p. 370). Reprinted by permission of Pearson Education, Inc., Upper Saddle River, NJ. 
As noted by the NRC (2003), many learning objectives for premedical students in introductory biology courses differ from those for students starting careers in the biomedical sciences (much less other biological areas) in those same courses. Even more so, the learning objectives for GE students differ from those for both student audiences discussed above. The AAMC's MCAT biology content specifications provide clear learning objectives for any introductory biology course in the United States required of premedical students by the AAMC (2011b) and offered for those students. No similar national statement of learning objectives for other student audiences enrolled in gateway biology courses, or their textbooks, exists. Individual academic departments establish separate learning objectives for students starting degree programs in biomedical sciences at each university. Similarly, individual colleges and universities establish the learning objectives for GE natural science courses as part of their overall GE graduation requirements.

In recognition of the different learning needs of these three student audiences, many institutions offer separate gateway biology courses for biology "majors" (which often include premedical students pursuing other undergraduate majors; AAMC, 2009c) and GE (or the alienating descriptor "nonmajor") students. To the extent that GE textbooks influence and reveal the curricula of these GE courses, they may not meet the CSL goals of the GE curriculum of which they are a component. The increasingly common practice of employing affiliated faculty to teach GE science courses (Kezar and Sam, 2011) can exacerbate the mismatch between an adopted textbook, the curriculum it supports, and an institution's GE goals. Affiliated faculty members often play little or no role in planning the curricula they teach, much less in choosing the textbooks. They also have little opportunity to understand an institution's GE goals.

Current economic constraints compel many American institutions to increase graduation rates and reduce costs (Kelderman, 2011). Schools encourage students to complete GE courses with more economical alternatives (Glenn, 2011), reduce GE requirements (Olson, 2010), and award GE credit for lower advanced placement test scores (Mendillo, 2012). The remaining GE courses shoulder a growing portion of higher education's mission to develop CSL among all college graduates. GE STEM courses need texts and curricula designed specifically to meet that mission. With renewed emphasis placed on the preparation of future biomedical researchers (NRC, 2003), reform of the MCAT (AAMC-HHMI, 2009), and the K-12 curriculum, especially in STEM (NRC, 2012), the time seems auspicious to distinguish the CSL learning goals of the undergraduate GE curriculum, especially in STEM, and coordinate it in a mutually supportive manner with the K-12 general STEM curricula and their current reform.

\section{ACKNOWLEDGMENTS}

R.E.J. Boerner, C. A. Breitenberger, L. E. Elfner, H. J. Graff, and two anonymous reviewers provided useful feedback and discussion on this project and earlier drafts of the manuscript; W. M. Froliklong and S. L. Terry assisted in textbook scans. Pearson Education, Inc., graciously permitted use of their artwork, which is included in Figure 5.

\section{REFERENCES}

Alberts B (2009). Redefining science education. Science 323, 437.

American Association for the Advancement of Science (AAAS) (1990). Science for All Americans: A Project 2061 Report on Literacy Goals in Science, Mathematics, and Technology, Washington, DC.

AAAS (2009). Vision and Change: A Call to Action, A Summary of Recommendations, Vision and Change Conference, Washington, DC. visionandchange.org/files/2011/03/Revised-Vision-and -Change-Final-Report.pdf.

American Association of Medical Colleges (AAMC) (2001). The MCAT Science Content Review, Part I: Report on the Medical School Survey of Science Content. www.aamc.org/students/ linkableblob/85392-2/data/monograph6-data.pdf (accessed 16 August 2011).

AAMC (2002). The MCAT Science Content Review, Part II: Report on the Surveys of Undergraduate Science Content. www .aamc.org/students/linkableblob/85394-2/data/monograph7-data .pdf (accessed 10 October 2009).

AAMC (2008). Percentages of MCAT Examinees Achieving Scaled Score Levels and Associated Percentile Rank Ranges by Area of Assessment, Combined 2008 Administrations. www.aamc.org/ students/download/85332/data/combined08.pdf (accessed 1 March 2012).

AAMC (2009a). First-Year Enrollees and Applicants to U.S. Medical Schools by Gender, 2009. www.aamc.org/download/68634/data/ enrollmentdata2009.pdf (accessed 1 March 2012).

AAMC (2009b). The Official Guide to the MCAT Exam, 1st ed., Washington, $\mathrm{DC}$.

AAMC (2009c). MCAT and GPAs for Applicants and Matriculants to U.S. Medical Schools by Primary Undergraduate Major, 2009. www.aamc.org/download/85996/data/table18facts09mcatgpabymaj1 web.pdf (accessed 30 January 2012).

AAMC (2010). Ratings of the Importance of Natural Sciences, Research Methods, and Statistics Topics on the MR5 Content Surveys (Draft). www.aamc.org/download/143506/data/ summer_2010_science_report.pdf (accessed 12 February 2012).

AAMC (2011a). Applicants, First-Time Applicants, Acceptees, and Matriculants to U.S. Medical Schools by Sex, 20002011. www.aamc.org/download/159590/data/table7.pdf (accessed 1 March 2012).

AAMC (2011b). Medical College Admission Requirements, 20122013, Washington, DC.

AAMC and Howard Hughes Medical Institute (2009). Scientific Foundations for Future Physicians, Washington, DC: AAMC.

Brooker RJ, Widmaier EP, Graham LE, Stiling PD (2008). Biology, Boston: McGraw Hill.

Campbell NA, Reece JB, Kaplan Testprep (2008a). MCAT/GRE Kaplan Test Preparation Guide for Biology, 2nd ed., San Francisco, CA: Benjamin Cummings.

Campbell NA, Reece JB, Simon EJ (2007). Essential Biology, 3rd ed., Upper Saddle River, NJ: Pearson Education.

Campbell NA, Reece JB, Taylor MR, Simon EJ, Dickey JL (2009). Biology: Concepts \& Connections, 6th ed., Upper Saddle River, NJ: Pearson Education.

Campbell NA, Reece JB, Urry LA, Cain ML, Wasserman SA, Minorsky PV, Jackson RB (2008b). Biology, 8th ed., Upper Saddle River, NJ: Pearson Education.

Freeman S (2008). Biological Science, 3rd ed., Upper Saddle River, NJ: Pearson Education.

Gallagher MC (2000). Lessons from the Sputnik-era curriculum reform movement: the institutions we need for educational reform. 
In: What's at Stake in the K-12 Standards Wars: A Primer For Educational Policy Makers, ed. S Stotsky, New York: Peter Lang, 281312 .

Glenn D (2011). CUNY faculty fears course-transfer proposal could jeopardize its say on curricula. Chronicle of Higher Education. April 20, 2011 http://chronicle.com/article/CUNY-Faculty -Fears/127217 (accessed 12 February 2012).

Kelderman E (2011). State officials say difficult changes are needed to help more students graduate. Chronicle of Higher Education August 10, 2011. http://chronicle.com/article/State-Officials-Say -Difficult/128600 (accessed 1 March 2012).

Kezar AJ, Sam C (2011). Understanding the new majority of nontenure-track faculty in higher education: demographics, experiences, and plans of action. ASHE Higher Educ Report 36, 1129.

Losos JB, Mason KA, Singer SR, Raven PH, Johnson GB (2008). Biology, 8th ed., Boston: McGraw Hill.

Mader SS (2009). Concepts of Biology, Boston: McGraw Hil.

Mader SS (2010a). Biology, 10th ed., Boston: McGraw Hill.

Mader SS (2010b). Essentials of Biology, 2nd ed., Boston: McGraw Hill.

Mendillo M (2012). Stop letting high-school courses count for college credit. Chronicle of Higher Education January 1, 2012. http:/ / chronicle.com/article/Stop-Letting-High-School/130183 (accessed 12 February 2012).

Miller JD (1998). The measurement of civic scientific literacy. Public Understand Sci 7, 203-223.

Miller JD (2007). Paper presented at the 2007 Annual Meeting of the American Association for the Advancement of Science, held 16 February 2007, in San Francisco, CA.

Miller JD (2010). The conceptualization and measurement of civic scientific literacy for the twenty-first century. In: Science and the Educated American: A Core Component of Liberal Education, ed. J
Meinwald and JG Hildebrand, Cambridge, MA: American Academy of Arts and Sciences, 241-255.

Miller JD, Scott EC, Okamoto S (2006). Public acceptance of evolution. Science 313, 765-766.

Muller HJ (1959). One hundred years without Darwinism are enough. School Sci Math 59, 304-316.

National Center for Education Statistics (2009). Bachelor's Degrees Conferred by Degree-granting Institutions, by Field of Study: Selected Years, 1970-71 through 2008-09. nces.ed.gov/ programs/digest/d10/tables/dt10_282.asp (accessed 8 November 2011).

National Research Council (NRC) (2003). BIO2010: Transforming Undergraduate Education for Future Research Biologists, Committee on Undergraduate Biology Education to Prepare Research Scientists for the 21st Century, Washington, DC: National Academies Press.

NRC (2012). A Framework for K-12 Science Education: Practices, Crosscutting Concepts, and Core Ideas, Washington, DC: National Academies Press.

National Science Foundation (1996). Shaping the Future: New Expectations for Undergraduate Education in Science, Mathematics, Engineering, and Technology, Arlington, VA.

Olson GA (2010). Why universities are streamlining their curricula. Chronicle of Higher Education, December 1, 2010. http://chronicle.com/article/Why-Universities-Are/125556 (accessed 12 February 2012).

Schmidt W, McKnight C, Raizen S (2002). Splintered Vision: An Investigation of U.S. Science and Mathematics Education, Ipswich, MA: Springer Science \& Business Media.

Snow CP (1959). The Two Cultures and the Scientific Revolution, New York: Cambridge University Press.

Zheng AY, Lawhorn JK, Lumley T, Freeman S (2008). Assessmentapplication of Bloom's taxonomy debunks the "MCAT myth." Science. $319,414-415$. 